\title{
Advanced Material-Technological Modelling of Complex Dynamic Thermomechanical Processes
}

\author{
Mašek Bohuslav ${ }^{1, a}$, Jirková Hana ${ }^{1, b}$, Malina Jiři ${ }^{1, c}$, Jeníček Štěpán ${ }^{1, d}$ \\ ${ }^{1}$ University of West Bohemia in Pilsen, Research Centre of Forming Technology, \\ Univerzitní 22, CZ - 30614 Pilsen, Czech Republic \\ amasekb@vctt.zcu.cz, bhstankov@vctt.zcu.cz, ${ }^{\mathrm{c}}$ mali@centrum.cz, ${ }^{\mathrm{d}}$ stepan.jenicek@seznam.cz
}

Keywords: Material-technological modelling, simulation, thermomechanical simulator, rolling wire

\begin{abstract}
Material-technological modelling has made great progress over recent years, thanks to the new possibilities opened up by developments in sensor technology, and especially in new methods of control, supported by innovative electronic elements and electronic circuits.

One such device, developed for material-technological modelling, is the thermomechanical simulator which was established in the laboratories of the Research Centre of Forming Technologies FORTECH, in Pilsen, in the Czech Republic. Thanks to new knowledge and technical equipment the majority of technological processes or even technological chains can be modelled. The most considerable and most important innovation in the material-technological modelling process is the significant acceleration and increased precision of the modelling process. The present technology even allows modelling of highly dynamic processes, such as wire rolling including all thermodynamical effects.

This paper presents the broad possibilities of the most modern material-technological modelling. The process of detecting technical and manufacturing problems during rolling and the possibilities of failure elimination are introduced in a practical example.
\end{abstract}

\section{Introduction}

Material-technological modelling is a tried and tested discipline, which has long been used to support designing for various technological processes. It has made significant progress during the last five years, mainly thanks to the new possibilities opened up by sensor development and especially by new control procedures supported by innovative electronic elements and circuits [1,2]. The thermomechanical simulator is one such device. This simulator enables precisely controlled deformations and temperature changes to be made in samples so that after the completion of the modelling process a structure is created with properties equal or similar to the structure and properties of the actual product. Thanks to new knowledge and equipment it is now possible to model a larger range of technological processes or even whole technological chains. The most significant and most important innovation in material-technological modelling procedures is a marked acceleration and improvement of modelling processes. Contemporary engineering units enable even highly dynamic and complex processes to be modelled.

\section{Experimental Procedures}

Material-technological modelling of complicated, complex and dynamic processes can be carried out using the special thermomechanical simulator which was built in the FORTECH Research Centre at the University of West Bohemia in Pilsen (Fig. 1). This simulator enables exact temperature courses and selected deformation parameters to be set as they occur in the real process, or as they could be in the case of development of new technologies or materials, with regards to structure. 
The simulator has a deformation component speed of up to $3 \mathrm{~m} / \mathrm{s}$ with the option of repeating any exactly controlled deformation course. Controlled gradients of over $100^{\circ} \mathrm{C}$ per second during heating and $250^{\circ} \mathrm{C}$ per second during cooling can be achieved for steels.

The process is of course precisely monitored. In addition to the TMT-simulator's own high-precision sensors, there are other external monitoring instruments available which can be connected to the control system. There is, for example, an optical pyrometer with automatic emissivity correction, a thermal camera and a high-speed camera to record the rapid deformation process in detail and help to analyse the crack creation process.

The structures achieved after real process and material-technological modelling were analyzed and compared via light and laser confocal

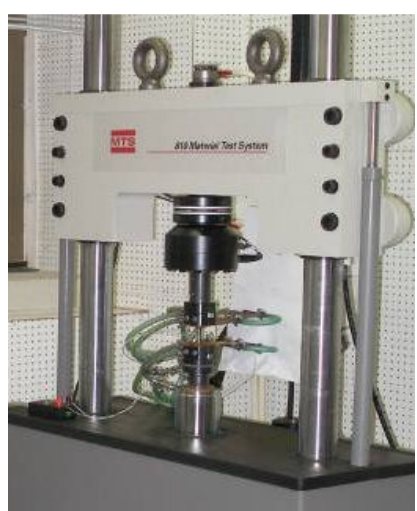

Fig. 1 Thermomechanical simulator microscopy. The mechanical properties were determined by mini-tensile test and hardness measurement.

Material-technological model of production process. A material-technological model of each real technological process is compiled from data captured during measuring on a real production line, whereas the rest of the data is provided by calculations or in the case of unavailability by educated guesswork. The following demonstration of the material-technological model shows an example of a wire rolling mill (Fig. 2). The modelled treatment of samples was carried out on the thermomechanical simulator. The temperature and deformation course of a process was programmed according to time dependence. The temperature of the sample was controlled by an electronic system. Controlled cooling was performed by an air stream, or, if necessary, water.
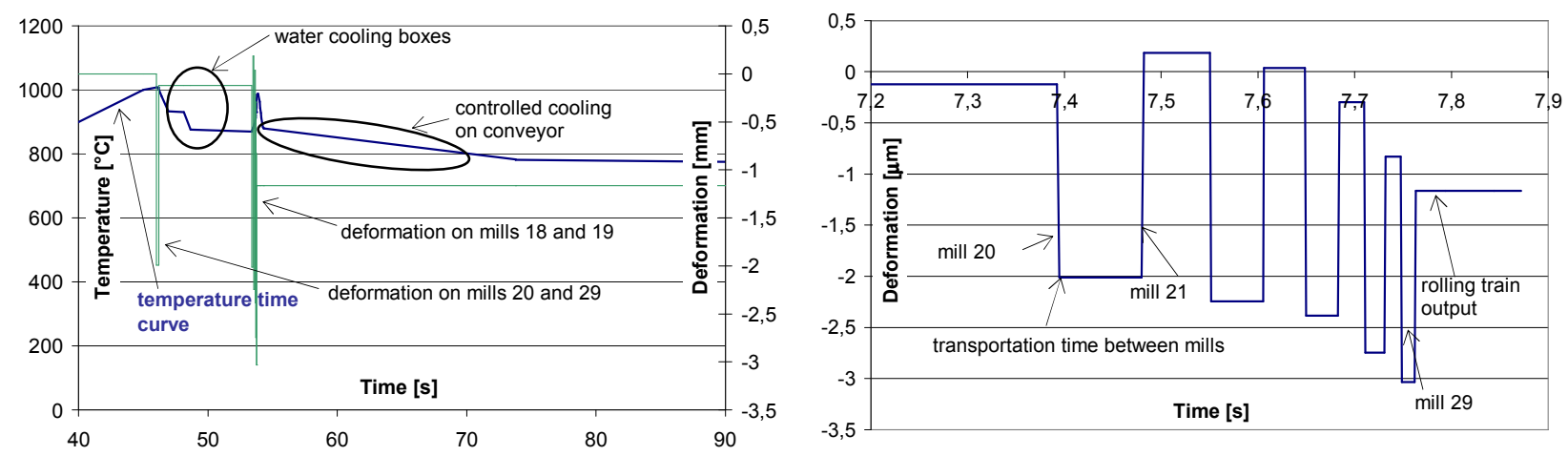

Fig. 2 Model, overall time-temperature and time-deformation course, with the deformation detail in finishing block

\section{Results and Discussion}

Initial state. Material-technological modelling works with samples of real material. A demonstration material-technological model was created for two low-carbon MnB steels (X1, X2).

The samples were taken directly from real manufacturing process, direct from the rolling mill.

The initial state of both model materials was composed of a ferritic-pearlitic structure with distinct texture in longitudinal section, typical of rolling.

The ferritic grain size and ferrite fraction were determined in the long- and cross-section of the material samples, and hardness HV10 and HV30 was measured. The ferritic grain size in the crossand long-section of both materials was in the range of 8 to $9 \mu \mathrm{m}$. No distinct deviation of the ferrite fraction between long- and cross-section was observed either. The ultimate strength reached $543 \mathrm{MPa}$ at the initial level for X1 steel and $524 \mathrm{MPa}$ for X2 steel. 
State after model treatment. After complete thermomechanical model processing, the samples of both steels were first analyzed metallographically. The structure was composed of ferrite and pearlite. The ferritic grain size was $7.3 \pm 4.9 \mu \mathrm{m}$ for $\mathrm{X} 1$ steel and $7.1 \pm 4.8 \mu \mathrm{m}$ for $\mathrm{X} 2$ steel.

No significant difference between the materials was observed when measuring the hardness HV10 and HV30. Hardness of about $150 \mathrm{HV}$ was measured in both steels. The ultimate strength reached over $510 \mathrm{MPa}$ in both materials. X2 steel showed ductility $\mathrm{A}_{5 \mathrm{~mm}}$ higher than $60 \%$.

Final state after complete rolling mill processing. Samples were taken for metallographic analysis and analysis of mechanical properties after complete technological rolling mill processing of the semi-product to a final diameter of $6 \mathrm{~mm}$. The material structure was ferritic-pearlitic. A distinct texture caused by rolling was again observed in long-section.

It was found that the thermomechanical treatment on the rolling mill caused ferritic grain refinement of ca. $2 \mu \mathrm{m}$ in both the longitudinal and transverse direction compared to the semi-product taken before it enters the final part of the rolling mill.

$\mathrm{X} 2$ steel hardness was ca. $141 \mathrm{HV}$ which corresponds to the hardness values measured in the long-section of the initial state samples, whereas hardness values measured in the cross-section dropped by $7 \%$. The hardness of X1 in both the cross- and long-section was about 10 points higher, which represents $7 \%$.

As is evident from the table of value deviations gained from the model and the actual process, the model conforms well with reality (Tab. 1). The deviation range is up to $10 \%$ for most of the deviations. Exceptions forming the parameters of the microstructure are caused by a considerable difference in the size of particular grains which then plays a significant role in the deviation of their geometric parameters and thus in the mean grain size value. Due to this great grain size dispersion, even a deviation of slightly above $10 \%$ can still be regarded as satisfactory.

Table 1 Relative percentage deviations of the model from the real product (identical material) [\%]

\begin{tabular}{|c|c|c|c|c|c|c|c|}
\hline & $\mathrm{R}_{\mathrm{m}}$ & $\mathrm{A}_{5 \mathrm{~mm}}$ & HV30 & HV10 & Size of ferritic grains & Ferrite fraction & KCV \\
\hline $\mathrm{X} 1$ & +1.6 & +3.7 & -1.3 & -1.3 & +11 & -6.5 & +12 \\
\hline $\mathrm{X} 2$ & -0.8 & +10.5 & +6.6 & +6.6 & +13 & -8.9 & +9 \\
\hline
\end{tabular}

Using the model for solving a technological problem. Uneven cooling intensity of the wire in form of the inclined screw on the cooling conveyer causes the deviations in structure development and in mechanical properties.

The loop passes through a coiling head which, at high speeds may occasionally lay the loops unevenly. Movement of the loop to the start of the conveyor generally leads to further uneven laying (Fig. 3).

This results in loops laying at the edge of the cooling conveyer are cooled more slowly because wires lay in two or even more layers. In contrast, cooling in the centre of the loop is faster because wires lie separately and spaced out. This arrangement, when more loops are piled together, can lead to unfavourable cooling conditions, which

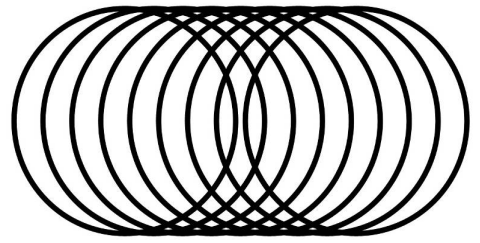

optimum distribution of loops on the cooling conveyor

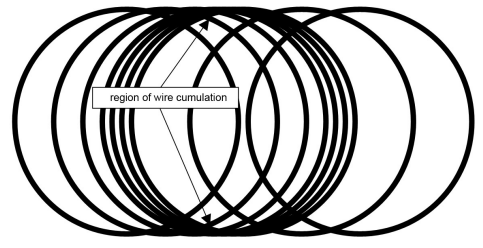

unfavourable, random, uneven distribution of loops with multiple overlapping

Fig. 3 Distribution of coiled wire on cooling conveyor can result in localized non-uniform properties along the length of the wire.

Therefore the basic model with mean temperature of wire cooling rate was modified, to describe the slowest cooling rate on the loop edge and the fastest cooling rate in the loop centre (Fig. 4). As far as material and microstructural properties are concerned, in the model of the loop edge a ferrite-pearlite structure originated with somewhat coarser ferrite grains of about $9 \mu \mathrm{m}$. These were the coarsest structures observed in all the variants under investigation. In the cooling model for the 
loop centre, this means at top cooling speed, ferrite grains of $8.5 \mu \mathrm{m}$ were observed in X1steel and for $\mathrm{X} 2$ steel the grain size was $7.1 \mu \mathrm{m}$. Accelerated cooling and the associated finer grain size caused an increase of hardness of $11 \%$ when compared to the loop edge (Fig. 5).

The mechanical properties of the real and modelled samples were also compared. The ultimate strength of the model of cooling at the loop edge was almost identical to the real state. The largest variations from reality were for ductility values, which were up to $15 \%$ (Fig. 5).

Deviations for notch toughness were $3 \%$ for X1 steel and $7 \%$ for X2 steel. There was also good

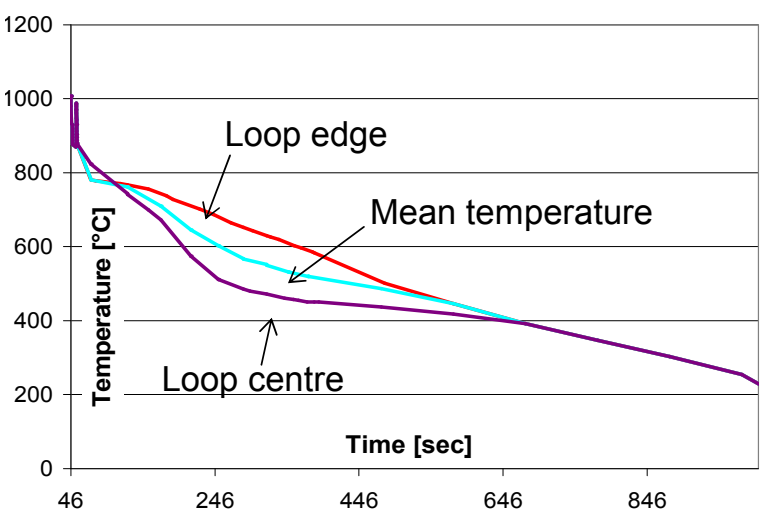

Fig. 4 Differing final cooling curves on the cooling conveyor for models of the loop centre, loop edge and mean cooling temperature agreement of ultimate strength values between the real product and the model for mean cooling rate. The greatest variations were again found to be for ductility values. The deviation was $7 \%$ for X1 steel and $9 \%$ for X2 steel (Fig. 5). The same trend was observed for models of the loop centre.

\section{Conclusion}

The model for real wire production was created with the help of material-technology modelling. The model was modified, after tests on a basic model, to display changes of microstructure and properties caused by uneven cooling rate at the edges and in the centre of

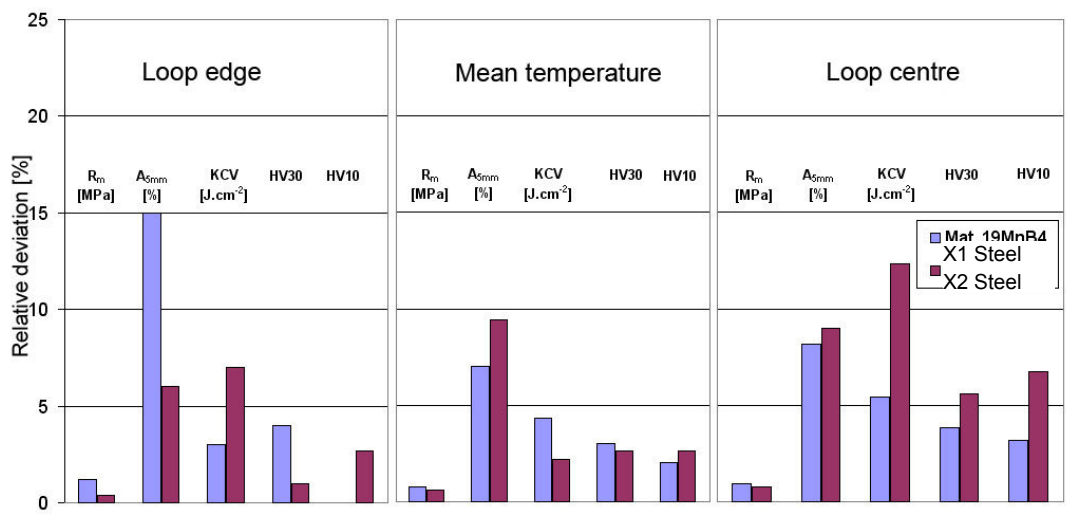

Fig. 5 Relative deviations of observed parameters coiled loops on a cooling conveyer.

The results showed that material-technology modelling can react with sufficient accuracy to variations in parameters which may arise in the real process. The agreement of the model with reality was mostly within 5\%. Only in exceptional circumstances did the variation exceed $10 \%$, meaning that none of the observed parameters exceeded a relative deviation of $15 \%$.

The experiment showed that material-technological modelling is a new, modern and efficient tool for optimizing technological processing chains and developing new technologies. It also enables very fast integration of new kinds of materials into production. Due to special techniques, just a small amount of material and energy is required for the thermomechanical simulator, keeping the costs for testing, optimizing and implementing new manufacturing processes into practice low. Completely new processing strategies can be tried out using material-technological modelling and new machines and devices can be designed and sized on the basis of the simulation results.

Acknowledgements. This paper includes results created within the project 1M06032 Research Centre of Forming Technology.

\section{Reference}

[1] B. Mašek, H. Staňková, J. Malina, L. Skálová, L. W. Meyer: Key Engineering Materials Vol. 345-346 (2007) p. 943

[2] B. Mašek, H. Staňková, D. Klauberová, A. Ronešová, in: Second Internatinal Conference on Heterogeneour Material Mechanics, edited by J. Fan, H. Chen DEstech Publications, Inc., USA (2008). 